EGU2020-11580

https://doi.org/10.5194/egusphere-egu2020-11580

EGU General Assembly 2020

(c) Author(s) 2021. This work is distributed under

the Creative Commons Attribution 4.0 License.

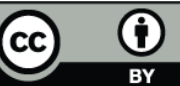

\title{
The variability and covariability of dissolved and particulate metal concentrations in the Rhine River
}

\author{
Marcel van der Perk \\ Utrecht University, Department of Physical Geography, Utrecht, Netherlands (m.vanderperk@uu.nl)
}

To predict the transfer and fate of metal contaminants in river systems, a thorough understanding of the factors controlling metal concentrations is essential. This study examines the variability and covariability of dissolved and particulate metal concentrations in the Rhine River at the Lobith monitoring station in the Netherlands in the period 2009 -2017. The data analysis concentrated on copper and zinc as these metals were not affected by limits of detection. The total copper and zinc concentrations are significantly linearly related to the suspended sediment concentrations. The intercept of this relation represents the mean dissolved metal concentration and the gradient the mean particulate metal concentrations. The thus estimated mean dissolved and particulate concentrations of zinc and copper resemble mean measured concentrations. For both metals, the particulate concentrations are only weakly positively correlated to the dissolved concentrations. This correlation can be attributed to the fact that both the dissolved and the particulate concentrations of copper and zinc are negatively related to river discharge, where the decline of the particulate concentrations in response to increasing discharge is relatively larger than that of the dissolved concentrations. When the particulate metal concentrations are standardised for the diluting effect of discharge, the standardised particulate metal concentrations do not correlate significantly with the dissolved concentrations. This may indicate that the sediment solid/liquid partition coefficients (Kd-values) for the considered metals vary considerably in time, although this hypothesis requires further investigation. 